\author{
ANNA PERUMALL \\ Goldsmiths University of London \\ aperu001@gold.ac.uk
}

\title{
AN EXPLORATION OF PARTNERSHIP WORKING BETWEEN THE YOUTH JUSTICE SERVICE AND THE MULTI-AGENCY SAFEGUARDING HUB \& FIRST RESPONSE TEAM IN RELATION TO SAFEGUARDING REFERRALS REGARDING YOUNG PEOPLE SUPERVISED BY THE YOUTH JUSTICE SERVICE
}

\begin{abstract}
The drive behind this paper is to explore the quality of the partnership working between the Youth Justice Service and the Multi - Agency Safeguarding Hub \& First Response Team in one of the London Boroughs on the basis of 6 selected cases which were known to both services. The study begins with an explanation of the rationale for the research and an introduction to both services and their roles. Subsequently, I review the literature, publications and relevant government policies linked to this topic. Successively, I concentrate on methodology employed in the study and any ethical issues arising as well as the theory underpinning the research. Next part presents the findings and offers an analysis. Finally, the paper outlines the conclusions of this piece of work with a brief summary of recommendations for both services in order to enhance the understanding of their roles as well as how to work better together in order to achieve improved outcomes for young people.
\end{abstract}

Keywords: youth services; government policy; justice service; safeguarding hub.

\section{INTRODUCTION}

The debate between welfare and justice approaches towards working with young people who offend continues to be active and dynamic. It is linked with understanding the origin and reasons for the offending behaviour of young people and the impact it has on the work undertaken with them. My personal view regarding work with young people who offend is closer to a welfare perspective, as after years of working with adolescents I feel that more engrained offending and risk taking behaviour is not only linked to poor parental care received in early childhood but also parental neglect in adolescence.

My research question was developed after discussions with an Operational Manager of a relevant Youth Justice Service and her desire for an exploration of the partnership working between the Youth Justice Service (YJS) and the MultiAgency Safeguarding Hub (MASH) \& First Response Team in relation to 6 selected 
cases. Our discussions indicated that whilst there are strengths in terms of collaboration between both services there is still a considerable amount of work needed to ensure that both agencies work well together. As part of this study I looked at the perspectives of both services in relation to 6 identified cases concentrating on the reasoning behind the referral to MASH; its outcome and expectation of Youth Justice Service in regards to the referral. My research question focuses on exploring the collaboration, communication and coordination of both services in relation to the needs and risks of specific young people known to both services.

This project will aim to identify the quality of communication between these services in relation to the identified cases by concentrating on looking at YJS's reasoning behind the safeguarding referrals for selected young people to MASH, and MASH's perspective and action in relation to these referrals. As such I will be interested in establishing whether YJS and MASH understood young people's needs and risks in unison or if there was a dissonance. Furthermore, I will be interested in establishing what is the understanding of each other's roles, remits, as well as decision making processes and how these impact on the partnership working between both services. Finally, I will aim to evaluate current practice by identifying barriers to good quality cooperation and I will aim to propose areas for improvement with a focus on better outcomes for young people.

\section{BACKGROUND INFORMATION}

Youth Offending Services (YOS) were set up across England and Wales as a result of the Crime and Disorder Act 1998 with the aim of reducing offending and re-offending as well as to provide support and rehabilitation to those who do offend (YJB 2003). YOS are multi-agency service which works with young people between the ages of 10 and 18 who committed an offence and are either in receipt of an out of court disposal, community or custodial sentence and is staffed by social workers, probation officers, police officers, case managers, substance misuse practitioners and specialists from health. The statutory aim of the service is set out by the Crime and Disorder Act 1998 as preventing young people from engaging in offending and anti-social behaviour. The YOS achieves this by delivering high quality, evidencebased interventions informed by a thorough assessment of needs and risk factors in partnership with young people, their families, the community and other involved agencies. The Youth Offending Service also provides Appropriate Adult Service of accompanying under 18's at the Police Station after their arrest in order to support them and ensure that they are treated fairly. The service is also obligated to work with victims of crime by providing support, guidance, an opportunity to influence the interventions for young people and an opportunity to take part in restorative justice conferences. Primary funding for the YOS is provided by central government and local authority standard funds, with additional finance provided by the Youth Justice Board (YJB) in the form of grants for specific projects. The YJB is a nondepartmental public body with overall responsibility for monitoring the performance and standards setting for the youth justice system. The YOS can also receive funding from various other sources, for example: Crime Disorder and Reduction Partnerships and Home Office. The Youth Offending Service is located within the Children and Families Department. 
The Multi-Agency Safeguarding Hub is the single point of contact for all safeguarding concerns regarding children and young people. Multi-Agency Safeguarding Hub (MASH), aims to improve the safeguarding response in relation to children and vulnerable adults through better information sharing, high quality and timely reaction to given concerns (HO 2014). After the referral is received its urgency is prioritised using rating which classifies the level of safeguarding concerns. Subsequently, the duty manger decides the best response to meet the child's needs and its timescales. This may involve referring the case to an Enhanced or Specialist service. If the referral requires an assessment then one of the First Response Social Workers is allocated and the assessment is concluded within 40 days. The assessing social worker gives a recommendation about the services needed or any action to follow after the initial assessment. The First Response social workers also take immediate investigative action in urgent child protection issues. Child Protection concerns are investigated under S47 of the Children Act 1989 and Child In Need Assessments are completed under S17 of the Children Act 1989. The MASH is composed of staff from different teams and partner agencies whose role is that of a consultant which include Probation, Police, Health, Education, Youth Justice, CASA professional, Housing and Transforming Families Teams. They conduct research on their database and then this information is shared in a confidential environment with First Contact Officers. It is positioned within the Children and Families Department.

It is quite common that both YOS and MASH are involved with the same service user at one time as illustrated in the research undertaken by the Youth Justice Board in 2010 which showed that $43 \%$ of young people known to the Youth Justice Service were also known to Children Services. This is when their partnership is especially crucial something that is at the heart of my inquiry.

To summarise, Youth Justice Service engages convicted young offenders intending to rehabilitate them with the aim of reducing offending behaviour, and MASH and First Response is a social work base, welfare orientated service which seeks to support vulnerable children and young people in crisis (Thomspson 2005 and Liebman 2007 cited in Fox et al. 2013: 3). MASH offers a more generic service with a wider remit whereas YJS is a specialist service. Furthermore, a perpetuating bifurcation between two services is the fact that YJS is placed under control of the Ministry Justice while the MASH as a welfare agency resides with local authority social services departments (Fox et al. 2013). Nevertheless, there is an overwhelming link between both services which in current times transpires to be more and more evident.

\section{LITERATURE REVIEW}

When reviewing literature in preparation for this study I have looked at three major areas which link with the topic of my paper namely welfare and justice debate in youth justice, links between parenting and onset of offending as I feel that this is the aspect that links the work of both services (YJS and MASH \& First Response) and makes their partnership working crucial; and literature relating to partnership working between Children's Services and youth justice in order to compare any previous exploration of this topic. Due to the need for conciseness I will only mention some aspect of these areas relevant for this study.

Welfare versus Justice Debate 
For much of its history youth justice has seen tension between welfare and justice approaches. The blend of justice and welfare has always been complex and the balance between the two has shifted considerably at times. Both have had unintended consequences with welfare stance compromising public safety for the sake of young person's needs, and a justice position ignoring individual needs and sometimes even human rights. Research presented by Briggs (2012) illustrated the struggle of the YOT practitioners in regards to the welfare and justice debate as one respondent commented:

"I think the reason that social workers feel uncomfortable often in the YOT is because they're not resourced to deal with the welfare issues... we're resourced to deal with the offending. So we have to pass on the welfare issues and sort of let go of them to a certain extent, which doesn't sit well with why anyone would go into social work (...) My ability to attend to welfare needs properly is severely constrained" (Briggs 2012: 23).

In the same research it was also noticed by some practitioners that it was impossible to focus only of offending as they felt that "the offence is a by-product of the things that have gone wrong in that young person's life which are on the main are welfare concerns" (Briggs 2012: 24).

The tensions between welfare and justice originate from the difficulties in fulfilling the principle aim of Youth Justice System to prevent offending whilst ensuring that the welfare of the child is considered. These difficulties occur especially when attempting to integrate policies and interventions to deal with the parallel needs of children and young people's welfare as well as offending as noticed by Smith (2005: 4). Additionally, conflicting aims and objectives of the different agencies required to meet the individual needs of children who are subject to youth justice intervention, contribute to the clash (Stephenson et al. 2007: 3) and this is at the origin of this inquiry. The proportional punishment and intervention to the gravity of the offence is as equally important as addressing the welfare needs that lead to the problematic behaviour in the first instance. To begin with basic reasons behind offending including poverty, housing, mental health, learning difficulties, substance misuse and poor parenting have to be addressed in order for the principal aim of Youth Justice System to be achieved.

\section{Parenting and offending}

When looking at the work with young offenders it is important to acknowledge that they are not only offenders but also victims of their life history and life choices (Fox et al. 2013: 3). The Children and Young Persons Act 1969 reflected the belief that offending by young people could be accounted for by the social conditions which they experience (Smith 2005: 4). Depending on the age of the child and their stage of development, the degree of influence that risk and protective factors will have on a young person's prosperity to offending will vary (Schofield et al. 2014: 30).

There are a number of studies suggesting that there is some coloration between conduct disorders, understood by persistent misbehaviour linked with offending which are related to the child itself for example Wooton (et al. 1997) demonstrated a possible strong relationship between "callous-unemotional' temperament and behaviour problems despite good parenting practices. Furthermore, there is some evidence according to Rutter (et al. 1970) that children with epilepsy or other cerebral function disorders, as well as those with cognitive deficits, are at risk of 
conduct and emotional disorders which can lead to offending. Nevertheless, there is overwhelming evidence that the parenting behaviour and parent characteristics, which I look at below, are amongst the strongest predictors of child behavioural problems (Marshall and Watt 1999) and are therefore linked with offending.

Exposure to risk at early age has been established to be associated with many later negative outcomes, mainly due to potential damage to the developing neurological system (Hinshaw 1992 cited in Schofield 2014: 31). The Department for Education report presented in 2010 found the main environmental factors linked with child anti-social behaviours were: parenting style especially a negative parenting style; maternal wellbeing in particular depression and stress, as well as the parents' relationship especially when violence was present (Scott 2010: 10). The same report also stated that there was no association (or a weak association) between family characteristics like social economic status and education, ethnicity, family structure and maternal age, therefore the link between anti social behaviour and disadvantaged backgrounds was not upheld in this study (Scott et al. 2010: 10). On the other hand, Farrington and West (1971) found that low family income, large family size, low intelligence and attainment as well as poor parental supervision predicted troublesome behaviours (Farrington 1989).

Farrington pointed out that McCord and Howard (1961, 1963) found that aggressive and violent adolescents tend to be parented during childhood by parents who are in conflict, apply poor supervision, were rejecting, punitive, whose discipline was erratic and they were aggressive and convicted themselves (in Farrington, D.P., 1989). According to Scott (1998) there are five aspects of parenting style that contribute to long- term association with conduct disorders, namely poor supervision, rejection of the child, parental disharmony, low parental involvement in child's activities and erratic harsh discipline. In terms of the latter one the National Society for the Prevention of Cruelty to Children (NSPCC 2015) reported a strong and consistent amount of research which links physical punishment with increased childhood aggression, anti-social behaviour and emotional and mental health of a child (Heilmann et al. 2015). Furthermore, Bowlby (1970) in his attachment model proposed that parental responsiveness was critical to the development of self - regulation skills. As pointed out by Johnson et al (2011) and Hirschi (1969) strong feelings of attachment to parents create a meaningful bond that the child would not want to jeopardise by engaging in delinquent behaviour. Moreover, poor interaction between mother and child can influence the child negatively in many ways. Scott pointed out (2010) maternal depression and stress as a risk factor as well as the fact that the establishment of a coercive pattern of parent-child interaction is likely to carry forward to a peer group interaction. There is a negative impact of lack of parental warmth on the child's self-concept which in turn can lead to negative behaviours. Further evidence suggests that martial conflict involving physical aggression has an impact on children's propensity to imitate violence towards family, peers and teachers (Marshall \& Watt 1999). Finally, violent and injurious parenting is regarded as the most influential risks for conduct disorders as it mostly causes physically maltreated children to be usually aggressive and non-compliant as well as use acting-out behaviours as regular behaviour patterns (Luntz \& Widom, 1994). Similarly, sexually abused children were found to be aggressive but also withdrawn (Erickson et al. 1989). 
Unarguably, parenting has the most important influence on a child's development in their early childhood but peer influence has more impact in association with socio-cultural context as the child becomes an adolescent which links with Crick and Dodge's (1994) social information processing model. This requires a good ability to encode and interpret social cues, search for an accurate response and evaluate them and lastly act (Schofield et al. 2014: 47). The evidence shows that deficit in social information processing predicts aggressive behaviour in the future (Schofield et al. 2014: 49).

Raws acknowledged that parenting adolescents is recognised as a challenging and complex task and can be exacerbated by household circumstances including depravation. It can be especially difficult as a balanced application of supervision and care is needed for it to be successful which is exemplified in Raws's research as he identified that 14-15 olds benefit from higher levels of some types of care and support than others (Raws 2016). For example the research indicated that 14-15 year olds benefited more from a 'medium' level of educational support as it allowed for their need for autonomy and choice which resulted in higher levels of life satisfaction but 'higher' levels of emotional support as this resulted in a positive well-being of the adolescents (Raws 2016). The finding of Raws's research further suggested that emotional support to teenagers is critical to ensure that they have a positive outlook on life and a sense of their own potential which in turn protect them from engaging in risk taking behaviours (Raws 2016).

\section{Partnership work and Youth Justice}

The issues of juvenile delinquency and how to respond to it have produced a voluminous body of literature and there is no dispute that it is a complex subject. Sections 6 and 7 of the Crime and Disorder Act 1998 encourage the development of local partnerships to provide a local framework and strategy for problems linked to crime in the given locality (Pickford \& Dugmore 2012: 90). Section 11 of the Children Act 2004 places duties on a range of organisations and individuals to ensure their functions have regard to the need to safeguard and promote the welfare of children (CA 2004: 11). The same act (Children Act 2004) also instructs Youth Offending Teams to tackle the underlying causes of offending whilst working within a multi-agency framework. This not only has consequences within the service, for example in terms of intervention plans aiming to address the individual needs of young people who come to contact with the youth justice system (CA 2004), but also in terms of linking with other agencies that may contribute to the positive outcomes of the individual. The Every Child Matters document 2003 also advocated for integrated working between all agencies which work with under $18 \mathrm{~s}$ to concentrate on the five key outcomes mentioned above (Wilson et al. 2011: 519).

There are limited studies into the partnership work between Youth Offending Teams and Children Services however I have discussed some below. Youth Offending Teams nationally are subject to regular inspection and in recent years they have mostly receive positive comments as the inspectors commented that 'partnership work was a key strength' (Criminal Justice Joint Inspection 2013 cited in Gray 2016: 60). Nevertheless, Gray (2016) points out that more independent research suggests a more negative picture, especially of the partnership between YOTs and children services as they fail to fully address the complex needs of the young people which are often multifaceted (Gray 2016: 60). It has been pointed out 
that the culture of encouraging collaborative working arrangements to address young people's welfare issues has unintentionally created tensions between YOTs and their social services partners due to incompatibility and clashing targets (Souhami 2009 in Gray 2016).

The research undertaken by Gray between 2011 and 2012 found that a source of tensions between YOT and Children Services were differences of opinion over thresholds or eligibility criteria which then potentially resulted in young people who offend not being effectively protected from harm and abusive relationships (Gray 2013 cited in Gray 2016). This was also pointed out in research conducted by Youth Justice Board in 2010 as it is noted that most practitioners who took part in the research thought that Children Service's thresholds were very high.

The Youth Justice Board research (2010) indicated much more positive findings in terms of partnership working on a strategic level than on operational level, as some significant issues were pointed out by practitioners regarding the protocols for joint working not being followed or being insufficient. The same research also found that there were protocols in place especially in relation to remands and referrals between services, however there was a lack of joint working in terms of sentencing planning for vulnerable children (YJB 2010: 51). Additionally, practitioners mostly felt that their judgment was overlooked (YJB 2010: 88).

Gray's research (Gray 2013 cited in Gray 2016) highlighted that YOT practitioners had a common view that there was an expectation from Children Services that YOT would complete any welfare related work required with young person once they were involved and this was a source of tension between services. Moreover, the Youth Justice Board research pointed out there was a level of frustration among YOT workers as they were concerned that Children's Services support for YOT clients was often not timely, not adequate, only reactive and consisted of the minimum practical support around money, benefits and accommodation, as well as that the situation was allowed to deteriorate before action was taken (YJB 2010: 88). This was also found by Briggs (2012) as YOT practitioners felt that Children Services action was not appropriate and exacerbated the risk of offending.

In the research by Youth Justice Board from 2011 it was noted that both YOT and Children's Services social workers had a common understanding that there were resource restrictions which impacted on quality of provisions which helped to level the conflict between two services around these issues. Nevertheless, the Youth Justice research showed evidence of good practice in terms of the partnership working of Children Services and Youth Offending Team with those young people who were leaving care and looked-after (YJB 2010: 88). The research conducted by Youth Justice Board in 2011 noted that most of the communication between YOT and Children's Services practitioners was conducted via telephone, email or during meetings and it effectiveness varied largely depending on individual workers.

\section{METHODOLOGY}

\section{CLASSIFICATION OF THE RESEARCH}

In this paper I will aim to depict certain phenomenon and look at how the researched population makes sense of their experiences in relation to it. Consequently, I will apply a qualitative method which is more exploratory and 
discovery-oriented (Bryman 2004 cited in Wilson et al. 2011: 257) therefore appropriate to explore meanings and perspectives of those from whom the data is gathered (Taylor et al. 2015).

\section{METHOLOGICAL DESIGN}

\section{TERMINOLOGY, RESEARCH QUESTION AND AIMS}

My research for the purpose of this paper is an exploration of partnership working between the Youth Justice Service and the Multi - Agency Safeguarding Hub \& First Response Team in relation to safeguarding referrals regarding young people supervised by the Youth Justice Service.

For the purpose of my research I will understand partnership working as an inter-agency collaboration, which involves respectful communication, early information sharing and a collaborative response to the issues presented by the services users focused on better outcomes for them. I will consider a situation where there is a risk to the life of the child/young person or likelihood of serious immediate harm "ill-treatment or the impairment of health or development" (CA 1989 and ACA 2002) as safeguarding concern.

As part of this study I looked at the viewpoints of both services in relation to 6 identified cases concentrating on the logic behind the referral to MASH; its result and actual expectation of the referrer, YJS, in regards to the referral. My research question focuses on investigating the collaboration, communication and coordination of both services in relation to the needs and risks of specific young people known to both services.

This project aims to identify the quality of communication between these services in relation to the identified cases by concentrating on looking at YJS's reasoning for safeguarding referrals for selected young people to MASH, MASH's perspective and action in relation to these referrals. As such I will be interested in establishing whether YJS and MASH understood young people's needs and risks in unison or if there was a dissonance, as well as what was the reason for this. Furthermore, I will be interested to establishing what is the understanding of each other's roles, remits as well as decision making processes and how that impacts on the partnership working between both services. Finally, I will aim to evaluate current practice looking for barriers to good quality cooperation and I will aim to propose the areas for improvement with a focus on better outcomes for young people.

\section{SAMPLE, RECRUITMENT OF PARTICIPANTS \& INTERVIEWS}

When planning my research I met with the Service Manager for the relevant YJS who was particularly interested in this study taking place. She had identified 6 cases that she felt would give the most information to satisfy my research questions as they had involvement from both YOS and MASH. My initial intention was to interview, in the face-to-face manner, the lead practitioners involved with the 6 identified cases respectively from both services which aimed to result in 12 interviews with 2 practitioners from each service discussing each of the 6 identified cases. Regretfully, due to the lack of availability of these workers this was not possible. I have then considered telephone interviews but again I did not succeed as the respective staffs' busy work schedule did not allow this. I also felt that they did not see their participation in the study as their priority which resulted in their 
reduced willingness to take part in the research. Nevertheless, both services identified senior team members with relevant knowledge to contribute to the research. Consequently, I conducted 1 interview with a Senior Duty Social Worker from Multi - Agency Safeguarding Hub \& First Response Team in relation to 6 relevant cases and 1 interview with 2 representatives of the management team in the Youth Justice Service relating to the same cases. I have adapted purposive sampling as the respondents had to have the required information (Kumar 2014: 244) due to the fact that my research question required respondents in position to provide me with the relevant information for the study, namely knowledge regarding the 6 identified cases.

I have chosen face-to-face interviews as my primary method as I aimed for this process to be as easy as possible for the respondents in order to support their participation; therefore I met with them in a convenient venue namely their place of work which I was also able to access without difficulty. This method also allowed me to give participants opportunity to discuss the questions and also allowed them to deviate from direct answers to the questions if needed. I was able to probe them in order to obtain in-depth information (Kumar 2014: 182) which also proved helpful. Moreover, this method gave me the ability to observe social cues from respondents and contributed to my better understanding of their experience relating to the researched phenomenon.

The interviews were semi structured as I had a series of questions prepared as part of an interview schedule (Appendix 2 and 3); however at times I asked additional questions (Bryman 2001: 110). The questions aimed to elicit factual information regarding the nature and outcomes of the referrals as well as each service's perspective in relation to the cases in question and were divided into 3 parts. The first part consisted of general questions regarding the role of the respondent in the respective service, their background, as well as a general question about decision making in relation referrals to $\mathrm{MASH}$, and for representatives from YJS their position on welfare and justice debate in relation to young people they work with. Questions in the second part concentrated on the reasons for the referral and the expectations following the referral, as well as the decision making which followed from the referral of the relevant cased by YJS to MASH. Final questions aimed to investigate the participant's understanding of the other service in terms of its role and remit as well as establishing the perceived quality of the partnership working, including any possible tensions and their knowledge about any current provisions in place which aimed to improve partnership working between YJS and MASH \& First Response.

The interviews were planned to last up to 1 hour and were audio recorded with participants' consent. I also attempted to apply a survey for more general questions relating to the partnership working between the Youth Justice Service and the Multi - Agency Safeguarding Hub \& First Response Team, however I have not received any responses from either team. All participants were employed either by the MASH and First Response Team or Youth Justice Service for over 6 months, they were females and their ethnicity was White. Interviews were conducted by one researcher.

The 6 cases discussed during the interviews with representatives from both services were identified by the Youth Justice Service as young people that were 
known to their service and were referred by them to MASH \& First Response. The diversity of these young people is included in table below.

Table 1. Basic data about research cases

\begin{tabular}{|c|c|c|c|c|c|c|c|c|c|c|}
\hline $\begin{array}{c}\text { Case } \\
\text { number }\end{array}$ & Age & Gender & Ethnicity & \begin{tabular}{|c} 
Family \\
Type \\
e.g. lone \\
parent, \\
stepparent
\end{tabular} & $\begin{array}{l}\text { Number } \\
\text { of } \\
\text { Siblings, }\end{array}$ & $\begin{array}{l}\text { Positioning } \\
\text { in the } \\
\text { family e.g. } \\
\text { middle child }\end{array}$ & \begin{tabular}{|c}
$\begin{array}{c}\text { Referral } \\
\text { received } \\
\text { by }\end{array}$ \\
MASH
\end{tabular} & $\begin{array}{c}\text { Initial } \\
\text { outcome }\end{array}$ & $\begin{array}{c}\text { Any further } \\
\text { involvement } \\
\text { with } \\
\text { Children } \\
\text { Social Care }\end{array}$ & \begin{tabular}{|c|} 
YJS \\
aware \\
of/or has \\
correct \\
info \\
regarding \\
outcome \\
\end{tabular} \\
\hline 1 & 18 & Male & No Info & No info & 2 & Oldest & Yes & $\begin{array}{l}\text { Single } \\
\text { Assessment }\end{array}$ & $\begin{array}{l}\text { Not yet } \\
\text { allocated }\end{array}$ & No \\
\hline 2 & 15 & Male & $\begin{array}{l}\text { White } \\
\text { British }\end{array}$ & $\begin{array}{l}\text { Step } \\
\text { parent }\end{array}$ & 3 & Oldest & Yes & $\begin{array}{l}\text { Single } \\
\text { Assessment }\end{array}$ & \begin{tabular}{|l} 
Child In \\
Need Plan
\end{tabular} & Yes \\
\hline 3 & 17 & Male & $\begin{array}{l}\text { White } \\
\text { British }\end{array}$ & $\begin{array}{l}\text { Step } \\
\text { parent }\end{array}$ & 3 & Oldest & Yes & $\begin{array}{l}\text { Single } \\
\text { Assessment }\end{array}$ & $\begin{array}{l}\text { No further } \\
\text { involvement } \\
\text { as parent } \\
\text { withdrew } \\
\text { consent }\end{array}$ & No \\
\hline 4 & 16 & Male & $\begin{array}{l}\text { White } \\
\text { British }\end{array}$ & $\begin{array}{l}\text { Step } \\
\text { parent }\end{array}$ & 7 & 3rd Oldest & Yes & $\begin{array}{l}\text { Single } \\
\text { Assessment }\end{array}$ & $\begin{array}{l}\text { No further } \\
\text { involvement } \\
\text { as parent } \\
\text { withdrew } \\
\text { consent }\end{array}$ & No \\
\hline 5 & 17 & Female & $\begin{array}{l}\text { White } \\
\text { British }\end{array}$ & \begin{tabular}{|l|} 
Step \\
parent
\end{tabular} & 3 & 2nd Oldest & Yes & $\begin{array}{l}\text { Single } \\
\text { Assessment }\end{array}$ & \begin{tabular}{|l|} 
Child In \\
Need Plan
\end{tabular} & No \\
\hline 6 & 17 & Male & $\begin{array}{l}\text { White } \\
\text { British }\end{array}$ & Mum/ Dad & 2 & Oldest & Yes & $\begin{array}{l}\text { Single } \\
\text { Assessment }\end{array}$ & $\begin{array}{l}\text { No further } \\
\text { involvement }\end{array}$ & No \\
\hline
\end{tabular}

Source: Self generated

\section{ETHICAL CONSIDERATIONS}

This research took into account universal ethical matters, consequently, it was conducted according to social work ethics and values and it was approved by Goldsmiths University's Ethics Committee. The topic area, questioning and structure of my research were agreed by the Head of the respective Youth Justice Service and the Service Manager prior to any individuals being contacted. All participants were consenting adults in a professional capacity, and were made fully aware of the research area and that their participation is voluntary and confidential. All information regarding particular cases was anonymised and destroyed after analysis; the reasons for potential need to breach confidentiality by researcher was explained prior to the commencement of the interview; all questions were shared with the service and participants prior to research commencing (Wilson et al. 2011: 257-258).

\section{DATA ANALYSIS}

After the data was gathered and prepared for analysis I applied thematic analysis, a process for encoding, translating of the qualitative information (Boyatizis 1998: 4) and identifying patterns in the data. I classified sub-themes in each of the interviews and I linked them together whilst considering my research 
question. This allowed me to derive recurring meaning and activities which I will present in Findings and Analysis.

\section{STRENGTHS AND LIMITATIONS}

One of the limitations of my methodology is that I was unable to wait to reach the saturation point, of no longer gathering new information as I was unable to expand our sample size (Kumar 2014: 243). Moreover, I was not able to monitor sample selection process as I was only able to speak to specific respondents who volunteered in the absence of availability of the relevant practitioners; therefore I was unable to eliminate any potential biases (Kumar 2014: 183). Similarly, the cases chosen for the research where selected by the Service Manager of the YJS therefore it is possible that this only showed more the problematic aspect of the researched phenomena rather than its successful examples. Furthermore, the sample was limited in the respondents' characteristics and was not fully representative of the diversity of the services' population. Finally, the sample size meant that the study is less easily generalised and it was more difficult to aggregate data and make systemic comparisons. The method applied was rather time consuming as it involved extensive investment of time from the researchers in order to complete, transcribe and analyse the interviews.

One of the strengths was that the interviews were conducted by one researcher therefore there was more of the probability that the quality of obtained responses was at the same level (Kumar 2014: 183). Furthermore, the researcher had an understanding of both services and their roles due to experience of working in both services as a practitioner prior to undertaking the research; however this could also be a limitation as this could give a possibility for some preconception about the findings.

\section{FINDINGS AND ANALYSIS}

The findings from this small scale research, completed as part of this paper were mostly in line with those from the research that was completed on a larger scale in previous years; however there were also some differences which I will point out below.

I have identified themes that I will list below, also referring to quotes from the interviews conducted as part of my research. In order to maintain confidentiality and anonymity of the participants I will be only identifying the service that they were from.

\section{WORKING TOGETHER OR IN ISOLATION}

It was very clear that working together was important to both YJS and MASH and First response as representatives from both services acknowledged this as a desired circumstance. MASH representative acknowledged that in "joint working we can talk it through together and kind of come up with more plans and think about roles and responsibilities, and how it's best to support families". This was also mentioned by Lord Lamming 2003 as he pointed out that "(...) effective support for children and families cannot be achieved by a single agency acting alone. It depends on a number of agencies working well together. It is multi-disciplinary task".

From the interviews with representatives from both services as well as sight of procedures relating to child protection, re-offending, looked after children as well 
as children remanded into custody and missing from education, it was clear that the strong protocols for joint working were in place. However, when it came to executing these in practice this was not evidenced, which was also noticed in research undertaken by YJB (2010), Gray (2016) and Briggs (2013).

"As per our shared procedures we referred a young person to MASH after we became that he committed an offence of sexual nature however the process was never followed up which was very disappointing." (YJS representative regarding case 1).

Both services seemed to be united by the same goal of achieving the best outcomes for children and young people and felt that the fact that they were part of the same service and under the same director contributed to their improved joint working. Local authority structure was also mentioned as a positive in the research by YJB (2010) as it proved that it was a benefit to be housed in the same building. Nevertheless, it seemed as if it was only an ostensible benefit in my research as representative from MASH said: "to be honest despite being in the same building I do not know a single YJS worker". Additionally, a YJS representative mentioned "we only separated by 11 floors but still it seems that it is extremely difficult to go and speak to each other face to face".

This research showed that YJS had a strong desire to work together with Children Services especially in regards to the 6 cases that they identified for this study. In all cases the YJS representative mentioned that their reasoning for referral to MASH was an expectation that YJS and MASH "might be able to work together" in one instance "to try and get him home" and "to keep the younger children in the family safe" (YJS Representative regarding case 1). Nevertheless, the YJS had an overwhelming feeling of working in isolation and as if their involvement with young people was invisible to the MASH and First Response Team.

"We were waiting for any communication from Children Services and there was nothing for very long time until we found out from the young person that they completed the assessment and the case is now closed. We could not believe it. It was as if we did not even exist as a service involved with this family" (YJS representative regarding case 3 ).

In case 4 again YJS reported that both agencies worked in isolation as they interacted with the family without consultation with each other which lead to confusion and incorrect information given to the family. This was especially in regards to the Social Worker from MASH and First Response who commenced the assessment: "I do not understand why the social worker just went there and told them all these things about the young person being on sex offender register which was completely incorrect. The poor family were distraught and all because the social worker did not feel like picking up the phone and taking to us" (YJS representative).

The YJS representative commented that this isolation of both services was a source of some worry for her in terms of possible loss of life of the young people she worked with: "the way it feels like, is like something really horrible is going to happen. For example that this kid has gone home and she ends up dead" (YJS representative). Such strong worries were not illustrated in the national studies in regards to youth justice, however agencies working as if they were working in complete isolation was identified by Hester 2011 in regards to Domestic Violence 
services and it was suggested as area for urgent improvement as it had potential to contribute to serious harm of the service users (Hester 2011: 850).

\section{KNOWLEDGE OF THE PARTNER AGENCY REMIT, THE SERVICES' OWN AGENDAS AND LIMITATIONS}

My findings showed that the fact that both MASH and YJS were not fully aware of their legal remits and its limitations lead to reduced ability to see the other service's perspective, and resulted in unrealistic expectations especially by YJS as they were not aware that "when, for example, a family does not want an assessment, (MASH) cannot make them have that assessment" (MASH Representative) due to the nature of the Section 17 of the Children Act 1989 to safeguard and promote their welfare of children 'in need'. It also states that the views of parents and children must be taken into consideration which could mean that the families can decline the service (CA 1989: 22). YJS often omitted to acknowledge this reasoning and expected an intervention from Children Services as they felt that action was needed but YJS more active involvement would criminalise the family and the young person as "there's sometimes and expectation on that (YJS) should imposed boundaries for young people on orders when the offence doesn't actually warrant it. The behaviour is completely out of control but there's no convicted offence that warrants that level of structure or monitoring or enforcement" (YJS representative).

Similarly, MASH representative added "on occasions it is a challenge that we have that we would like to put more support in place and do an assessment to assess the need. If a family says no, we can't override that unless we've got child protection concerns, and especially for that is quite high, because otherwise, you'd be living in a state where, you know, if the local authority wanted to be involved, they would be involve just about anything and that's not okay." (MASH Representative).

This has not been present in this degree in research of a bigger scale as it was seen more of an issue linked to threshold. As such, if it is considered that the child is likely to suffer significant harm without social work intervention, then assessment should be carried out under Section 47 and consent is then not required, but parents should be informed of the change of approach and the reasons for the concerns (CA 1989). The cases of this status created less ambiguity for both services.

Additionally, the MASH Representative acknowledged that her knowledge was limited regarding the work of YJS and she pointed out that that could have impacted on her readiness to consult them. "I do not really know what YJS does apart from the fact that they work with young people who offend; I am simply not aware of their specialist knowledge or legal remit".

The YJS's main concern was that their remit did not allow them to accommodate young people or complete child protection investigations and these were 2 main reasons for the referrals to MASH \& First Response, however MASH representative felt the young people should not be accommodated away from home lightly.

On a separate note, it was pointed out by the YJS representative that the partnership working with MASH was significantly better when the social worker from MASH \& First response had a direct experience of working within the YJS, and therefore had knowledge of both services. 


\section{INFORMATION SHARING \& COMMUNICATION}

Information sharing and communication has been pointed out as one of the biggest challenges of the partnership by Youth Justice Service. This has also being pointed out by the Home Office when evaluating the work of MASH (2014). In this report it was noted that there was common misunderstandings among professionals about what information can be shared, this included practitioners withholding information too frequently and the risk of sharing information was perceived to be higher than it actually was. These misunderstandings were perceived to have led to anxieties over information sharing, and seen to ultimately have held back interagency collaboration and effectively safeguarding individuals. (HO 2014)

"It is important for us to consider the requirements of the Data Protection Act and Human Rights Act when sharing information regarding families we work with as it could have potential implication in terms of legal litigations against local authority when the information is shared unlawfully" (MASH representative). The Data Protection Act 1998 (DPA 1998) makes the processing of this information subject to a number safeguards namely that there has to be clear consent given to share the information by the person that the information relates to. The exemption applies when the information sharing is justified by reference to the legitimate aims (e.g. prevention of crime or protecting the rights of others) provided that the interference is necessary and proportionate (DPA 1998). This has been additionally strengthened by the Article 8 of the European Convention of Human Right (1970). Consequently, this inevitably impacts on MASH's level of information sharing with partner agencies including YSJ which could be mistaken for lack of consultation or communication.

In terms communication in all 6 cases YJS reported poor communication from MASH and in 5, YJS was not informed of the outcome of the referral:

"all week we've been trying to find out the outcome of the Section 47 referral and what's happening. And we were really concerned as because this kid hasn't been into see us since. And the social worker said oh, she went home last week. Wait a minute, but there are bail conditions for the mother and not to.... and you were doing a Section 47 on her. Oh, she has withdrawn her allegations. Oh. And I think, you know, tell us. So we said so what's the ongoing safeguarding concern of this kid then, 'cause just because she's withdrawn the allegations don't mean she... I mean, she was... the ambulance crew described her injury as quite significant".

In terms of another case YJS expressed similar frustration:

"But whatever the reason was, why did they not pick up the phone to talk to us? They didn't have to tell us exactly what they were doing but, that's the process by which they've been instructed to do that, why didn't they talk to the people A, that referred to them in the first place and B, that were part of that panel where that decision was made?" (YJS Representative).

The above shows that communication between YJS and MASH could be improved, however it is likely that YJS's frustration regarding lack of communication is mostly linked with the fact that most of information sharing for YJS is exempt from the restrictions as in line with the Crime and Disorder Act 1989 the information can be shared if its purpose has public safety in mind or for the 
purpose of a risk assessment, therefore it can be argued that any information sharing conducted by YJS has one of these or both in regard (CDA 1989).

My research also showed that there was significant misunderstanding in terms of what information should be included in the referral to MASH and what they concentrated on when making a decision about providing a service. This was illustrated in comments by MASH representative stated when analysing one of the referrals: "this information does not mean anything to us...he is in a relationship which is not appropriate.... well is part of adolescent development, it does not warrant our involvement. We need more specific information about the risks for this young person." In turn, in relation to the same case, YJS commented "if we have known what information MASH needs specifically we would have not given them the reams of information but limit it and focus on the most concerning aspects."

\section{PROFESSIONAL JUDGEMENT, SPECIALIST KNOWLEGE \& SKILLS}

The MASH representative who took part in this research has commented that in her view "Youth Justice colleagues were producing very comprehensive reports which were comparable with single assessments." Nonetheless, it was quite clear that the YJS had a sense of being disregarded and not trusted in terms of their judgement:

"we work within a well-being model and most of our young people are at the highest end but we do not refer to MASH so when we do we would like to think that MASH will trust our judgments as if we referring that must mean the situation will not improve until there is a different approach, an intervention" (YJS representative). It also seemed that there were gaps in terms of knowledge amongst YJS and MASH regarding each other's work remits, discussed above, which lead to a lot of frustration from YJS's point of view.

Being able to build rapport with service users is very important to social work and crucial for working with adolescents who are involved in offending as they might be a difficult group to reach due to issues of low self-esteem and the effects of labelling common for this group (Pickford \& Dugmore 2012). YJB (2009) inquiry into Children, Schools and Families Committee inquiry into Training of Children and Families Social Worker noted that current social work degree continued limited input and therefore social workers were not prepared to work with young people who offend. This was also pointed out by the YJS representative as she felt that the social worker from MASH struggled to interact with one of their clients and it had an impact on the work she was able to complete with him:

"The social worker proceeded to get out his book and read this story to him, which was clearly aimed at four or five-year-olds. And he got increasingly frustrated (....) and at one point, he turns to him and tells him, "Do I have to stay for this shit? (....) She had no concept of the impact of what she was doing, she wasn't talking to him. She wasn't communicating with him. She seemed unable to display anything or communicate with him" (YJS representative).

\section{CHOICE OF INTERVENTION \& THRESHOLDS}


Everyone who works with children, including a number of professionals amongst others police, have a responsibility for keeping them safe (WTSC 2015). My findings indicate MASH felt in line with this as they saw safeguarding as everyone's responsibility and proposed that YJS arranges Team Around The Child Meetings in order to address the needs rather than refer to their service:

"I think safeguarding is everybody's responsibility. And whilst they (YJS) may have a specific focus on, you know, court orders and so forth, they could also complete a Team Around a Child Meeting or Team around the Family around a family meeting, and within that, invite other agencies they'd like to refer to you and then refer them on to my future's transforming families, you know, whatever other service." YJS representatives did not consider this as an option however it is not clear it this was due to low familiarity of this practice or to low effectiveness of this approach. I am aware that in one of the local authorities this approach has not been successful when applied by YJS as there were confusion about who the lead professional would be and the voluntary aspect of it meant that it has not been sustainable with more complex families with tendency to disengage who majority of YJS's clients.

The MASH representative also felt that preventative work would give the best outcomes. This was also pointed out by Munro (2011) as she established the "preventative services can do more to reduce abuse and neglect than reactive services" (Munro, 2011). Preventative measures were also recognised in influencing offending as government introduced a number of measures between 1933 and 2008 to enforce parents bringing children up more responsibly that included parenting contracts to be given to parents of young people on Anti Social Behaviour Orders and establishment National Parenting Academy in 2007 (Mooney 2003 cited in Muncie 2009)

Additionally, the MASH representative believed that talking with families prior to implementing an intervention was a priority as well as completing work prior to suggesting accommodating of the young person out of the family home. On the other hand, YJS saw this as a safety issue and felt that lack of consultation with them in this respect puts young people at risk:

"after so much time of building relationship with the young person, she discloses this horrific abuse and we refer to MASH hoping that they will speak to us regarding the strategy for handling this and what do they do they go speak to the parents. The young person then withdrew the allegation and was put back in a risky situation. She also lost trust in us as in her eyes we failed to protect her." (YJS representative).

Whereas MASH seemed to not be aware of this and was constantly struggling with the amount of referrals they receive and processing them:

“(...) on average, in MASH we get somewhere around 350 referrals a month.

So actually what sometimes partner agencies referring in, that will for them be the most worrying case they've had in a long time. So they referred it, and of course this going to get an assessment in their eyes. But actually we may have seen 60-70 other cases that week which are worse or you know, a little bit worse. And actually that means then we're like, 'Well, no, actually it's not that bad."

MASH also justified not acting in the case when YJS worker was involved and this is something which was also evident in previous research (Gray 2016): 
"when we're seeing things day in and day out which are pretty awful, then actually you know, a young person who's got a YJS worker, who's kind of engaging with services and doing okay, that isn't going to be the one that we think needs to have a child in need plan. And I appreciate I've been really flippant with that comment because that's probably not a fair presentation of the referrals that they're sending in" (MASH representative). YJS on the other hand felt that if they did refer to MASH that meant that they have exhausted all other avenues and they assessed that service from a core social care service was essential: "I really struggle to understand why MASH does not believe our professional judgement, if we do refer that means nothing else has worker and we are really concerned" (YJS representative)

MASH representative also recognised that there is a phenomenon of desensitisation amongst MASH Team as this is their behavioural strategy to deal with secondary trauma (Dorr 2014) every day therefore she felt it was possible that some referrals were not progressed beyond screening stage as were not seen as serious.

"I guess there is a risk that when you do kind of long-term screening work and working in the MASH team, you get a bit fatigued you know, you don't see risk in the same way. And that's why we have reflective supervision to try and encourage us not getting too tired with things and to kind of see the bigger picture" (MASH representative).

This either resulted in delayed or no action in regards to the cases referred by YJS which build up their frustration or in 2 instances lead to sentencing including that the young person was ordered by the court to residence as directed by the local authority:

"due to MASH \& First Response non-action the court decided to remand this young person to local authority care as it was clear that he will continue his reckless and dangerous behaviour if he remains at home. This meant that the young person had to be accommodated and allocated social worker from Children Service as a direction of the court". (YJS representative)

MASH acknowledged that the thresholds were high and this was a result of the amount of the referrals received daily, however YJS questioned this as neglecting young people needs and similarly to Gray (2016), questioned if the young people who offend are being effectively protected from harm and abusive relationships (Gray 2016) due to high thresholds.

The MASH representative acknowledged other services' disappointment at the threshold levels but also felt that it was justified: "it's right that the threshold for that is high, but that can be frustrating to our partner agencies where they want to us to take further action... I would look at what the risk factors are and what the protective factors... what interventions have been tried before and how many services are in place". (MASH Representative).

On the other hand YJS expressed some concerns relating to this: "It is my worry that young people who are known to our service are not protected, not safeguarded by the local authority as is seems that it is somehow all their choice to be in the mess that there are in" (YJS representative).

\section{DISCUSSION AND CONCLUSION}


It is important to mention that this research's findings are not universal and cannot be generalized especially due to its small scale and limited timeframe. Nevertheless, there are a number of similarities between my findings and current available research which suggests some accuracy and provides helpful knowledge in informing future social work practice.

The indisputable findings of my research were in line with the document Working Together to Safeguard Children namely that to everyone who works with children, including a number of professionals amongst others police, have a responsibility for keeping them safe (WTSC 2015). Young cited in Pickford and Dugmore (2012) also argued that interventions to address crime and disorder must be coordinated and must involve a uniform approach and again I feel that this has also been confirmed by this research. Additionally, due to the vast amount of evidence suggesting very strong links between parenting and offending mentioned in the literature review it is crucial that Youth Justice Service work in the multidisciplinary manner as intended by the Crime and Disorder Act 1998 as well as in partnership with other agencies especially Children Services. Finally, it is useful to acknowledge the welfare and justice debate in response to youth crime and how this interacts with managing risk to the public.

My findings suggested that there were strong protocols present within both services to facilitate joint working however when it come to executing these in practice this was not evidenced, which was also noticed in research undertaken by YJB (2010), Gray (2016) and Briggs (2013). As such, YJS had an overwhelming feeling of working in isolation and as if their involvement with young people was invisible to the MASH and First Response Team. Thus, it is fair to say that both services would benefit from recognising this and aiming for improvements in this area. Furthermore, information sharing and communication has been pointed out by YJS as one of the biggest challenges of the partnership with MASH. Correspondingly with national research my findings suggested that there was common misunderstandings amongst professionals about what information can be shared which lead to practitioners withholding information or not communicating at all.

Currently, there are a number of key drivers for change in youth justice namely, reduced caseloads which have fallen by over $70 \%$ since 2007 , complex needs linked to welfare, health and education of the young people who remain in the system, as well as reduced budgets (Taylor 2016). As Youth Justice is evolving in this context the Government commissioned Charlie Taylor to conduct the national review which is underpinned by the following principles: the need for a shift in the way society and government approaches youth justice so that again we start to see the child first and the offender second, as well as the fact that the causes of childhood offending are situated beyond the reach of the youth justice system (Taylor 2016). Similarly as my findings, the review highlights the need for integrated multiagency responses to child offending, the importance of intervening early with vulnerable children and families as well as the need for a more proportionate response to offending. Taylor (2016), states that there is a need to understand and address young people's behaviour in the context of their family, school and community, a theme that also has been highlighted by this small research. Taylor (2016) finds restorative, relationship-based, skills-based and family focused approaches to be the most effective in preventing offending and reoffending. As 
such, youth offending teams across the country are increasingly integrated within children's services which might be the future for the service I have conducted my research in. As this stance progresses it is essential to acknowledge and take into consideration that practitioners working with young people who offend required a specialist set of skills and knowledge which generic social workers often lack. This was also confirmed by my findings. MASH Representative, I spoke to agreed that her knowledge was limited in regards the work of YJS and in her opinion they were specialist in the area of juvenile delinquency. This was also present when engaging young people who offend by MASH practitioners as they struggled to interact with young people and it had an impact on their work. The fact that social workers were not prepared to work with young people who offend was also recognized by YJB (YJB 2009).

In YJB's research from 2010 further tensions between partnership working of both services were pointed out as there was a level of frustration among YOT workers as they were concerned that Children's Services support for YOT clients was frequently not timely, not adequate, only reactive and consisted of the minimum practical support around money, benefits and accommodation as well as that the situation was allowed to deteriorate before action was taken (YJB 2010: 88). Furthermore, there were differences of opinion over thresholds or eligibility criteria which then potentially effected in young people who offend not being effectively protected from harm and abusive relationships (Gray 2013 cited in Gray 2016). This was also pointed out in research conducted by Youth Justice Board in 2010 as it noted that most practitioners who took part in the research thought that Children Service's thresholds were very high. Similarly, Briggs found (2012) that YOT practitioners felt that Children Services action was not appropriate and exuberated the risk of offending. This was also consistent with my findings as YJS reported that in majority of the cases looked at as part of my study, MASH did not act and this lead to an escalation of behaviour and criminalising young people. In my view there is a combination of reasons for this. On one hand it is linked with thresholds but on the other with complexity of assessment of adolescents' safeguarding needs. This was also mentioned in research completed by Raws which evidenced that adolescent neglect can be missed and is poorly responded to partly because of the incorrect assumptions that teenagers are naturally resilient (Raws 2016). More significantly, Raws pointed out that it is because the safeguarding responses do not differentiate between younger children and older children (Raws 2016). As such, it is my view there is a misunderstanding of the safeguarding needs of adolescents which are voiced by the specialist services which can lead to certain young people not being provided with a safeguarding intervention from social care service therefore further training is needed in this area.

I have noticed a number of strengths in both researched services when working with young people affected by crime, namely YJS's understanding of that "welfare needs can affect the child's reaction to the world and at times resulted in offending" (YJS representative) as well as MASH and First Response stress on involving families before any draconian action is applied and working together with them. Nevertheless, there are definite areas for improvement linked to partnership working of these services which mainly concentrate around enhanced communication and simultaneous consultation. As such, it seems that both services would benefit from understanding each other's perspective by learning more about 
the operations and day to day life of each other's roles. This should include information about each other's remit, legal context and data protection and information sharing practices as well as information about making referrals as it appeared that vast majority of referrals to MASH were rejected due to lack of clear and substantiated information about the safeguarding issues in particular cases. Additionally, there appears to be a clear need for standardised and up to date records keeping that can be shared across YOTs and Children Services as it seemed that access to each other's case management systems could be helpful, although the confidentially protocols would need to be agreed. This was also mentioned in the research conducted by YJB in 2010 (YJB 2010: 88).

\section{IMPLICATION FOR SOCIAL WORK PRACTICE}

The research highlighted a numbers of applications relevant for social work. Firstly, the importance of applying social work values and ethics when working with young offenders and anti-oppressive practice, non-judgmental approach and accepting the process of change as a continuum which can only take place with holistic and coordinated support.

Moreover, there is a need for social workers to be knowledgeable and have understanding of the work done by other agencies and not becoming comfortable within only one field of practice. It became clear from the research that services at times become too fixated on their own approach and it affected the service given to service users as well as the quality of partnership working.

Participants' narrative suggested that partnership working was well set up. From the interviews with representatives from both services as well as sight of procedures relating to child protection, re-offending, looked after children as well as children remanded into custody and missing from educations it was clear that the strong protocols for joint working were in place however when it come to executing these in practice this was not evidenced, which was also noticed in research undertaken by YJB (2010), Gray (2016) and Briggs (2013). As such some of the aspect of the partnership working could be improved especially communication and collaboration between Youth Justice Service and MASH when working with the same service users, to avoid the risk that the services will work in isolation and have a feeling of clash of principles. (Hester 2011: 850).

This research confirmed that policy makers ought to concentrate on ensuring that multi-agency responses towards youth crime are well coordinated, interconnected and solid. It is also crucial that the right balance is found between constrains of a punitive system of accountability and responsibility versus individual needs. Social workers within both teams, Youth Justice Service and MASH and First Response ought to bear in mind the overarching intentions of social work to empower, engage in non-judgmental manner whilst promoting the well-being and interest of young people in an anti-oppressive and antidiscriminatory framework as this can easily be lost amid in these circumstances (Fox at al 2013: 11). Furthermore, it is crucial that young people are treated with fairness, dignity and respect, with special sensitiveness to factors of difference which may pose a barrier to their engagement such as gender, race, religion, language, health, learning difficulties or experience of trauma and more importantly the fact that they have offended. According to YJS's representative, 
this last aspect often lead to non-involvement of MASH as the presented difficulties were viewed as linked with offending rather than safeguarding need.

\section{REFERENCES}

Audit Commission. 1996. Misspent Youth...Young People and Crime. Oxon: Audit Commission Publications.

Bailey, Roy V. and Brian Williams. 2000. Inter-agency Partnerships in Youth Justice: Implementing the Crime and Disorder Act 1998. Sheffield: University of Sheffield, Joint Unit for Social Service Research.

Blaikie, Norman. 2010. Designing Social Research. Cambridge: Polity Press.

Bowlby, John. 1970. Attachment and Loss. Vol. 1. London: The Hogarth Press.

Boyatizis, Richard E. 1998. Transforming Qualitative Information. Thematic Analysis and Code Development. London: Sage Publications.

Briggs, Damon B. 2013. "Conceptualising Risk and Need: The Rise of Actuarialism and the Death of Welfare? Practitioner Assessment and Intervention in the Youth Offending Service." Youth Justice 13(1): 17-30.

Bryman, Alan. 2001. Social Research Methods. Oxford: Oxford University Press.

Burnett, Ros and Catherine Appleton. 2004. "Joined-Up Services to Tackle Youth Crime.” British Journal of Criminology 44(1): 34-54.

Cawson, P., Watton, C., Brooker, S. And Kelly, G. 2000. Child Maltreatment in the United Kingdom: A study of the prevalence of child abuse and neglect. London: NSPCC.

Dorr, C. 2014. Social Work Live: Theory and Practice in Social Work Using Video. Oxford: Oxford University Press.

Erickson, M.F., Egeland, B., Pianta, R. 1989. "The effects of maltreatment on the development of young children." Pp. 647-684 in Cicchetti and Carson, V. (eds.). Child Maltreatment: Theory and Research on Casuses and Consequences of Child Abuse and Neglect. New York: Cambridge University Press.

European Convention of Human Rights, accessed on 29.08 .15 at 23.07 http://www.echr.coe.int/Documents/Convention_ENG.pdf, [online]

Every Child Matters (ECM). 2006. What to do if you are worried a child is being abused. Department for Education.

Farrington, D.P. 1989. "Early Predictors of Adolescent Aggression and Adult Violence." Violence and Victims 4(2): 79-100.

Fox, D., Arnull, E. 2013. Social Work in the Youth Justice Service System. A multidisciplinary perspective. Maidenhead: Open University Press.

Gray, P. 2016. "Child friendly international human rights standards and youth offending team partnership." International Journal of Law, Crime and Justice 45: 59-74. 
Heilmann A., Kelly, Y., Watt, R. G. 2015. Equally Protected? A review of the evidence on the physical punishment of children. Report commissioned by the NSPCC Scotland, Children 1st, Barnardo's Scotland and the Children and Young People's Commissioner Scotland.

Hicks, L., Stein, M. 2010. Neglect Matters. A multi-agency guide for professional working together on behalf of teenagers, Department for Children, school and families.

HM Government. 2015. Working Together to Safeguard Children (WTSC). Department for Education.

Home Office. 2014. Multi Agency Working and Information Sharing Project. Final Repor. Home Office.

Huang, H., Ryan, J.P., Herz, D. 2012. "The journey of dually-involved youth: The description and prediction of rereporting and recidivism." Children and Youth Services Review 34: 254-260.

Johnson, W. L., Giordano, P.C., Manning, W. D., Longmore, M., A. 2011. "ParentChild Relationship and Offending During Young Adult Hood.” Journal of Youth Adolescence 40: 786-799.

Kumar R. 2014. Research methodology. A step-by-step guide for beginners. Fourth Edition, London: Sage.

Lord Laming. 2003. The Victoria Climie Inquiry, Report of an inquiry by Lord Laming.

Luntz B. K., C. S. Widom. 1994. Antisocial personality disorder in abused and neglected children grown up, The American Journal of Psychiatry 151(5): 670674.

Marshall, J., Watt, P. 1999. Child Behaviour Problems: A Literature Review of the Size and Nature of the Problem and Prevention Interventions in Childhood. Perth, Western Australia: The Interagency Committee on Children's Futures.

Mercer, N., Farrington, D.P., Ttofi, M.M., Keijsers, L., Branje, S., Meeues, W. 2016. "Childhood Predictors and Adult Life Success of Adolescent Delinquency Abstainers.” Journal of Abnormal Child Psychology 44: 613-624.

Munro, E. 2011. The Munro Review of Child Protection: Final Report. A childcentered system, Department of Education. HMSO.

Muncie, J. 2009. Youth and Crime. London: Sage Publications.

Muncie, J., Hughes, G., McLaughlin, E. 2002. Youth Justice. Critical Readings. London: Sage Publications.

Pitts, J. W. 1999. Working With Young Offenders. London: British Association of Social Workers.

Pickford, J., Dugmore, P. 2012. Youth Justice and Social Work, Second Edition London: Sage Publications Ltd. 
Raws, P. 2016. Understanding Adolescent Neglect: Troubled Teens. A study of the links between parenting and adolescent neglect. The Children's Society.

Rutter, M, Tizard, J. Whitmore, K. 1970. Education, health and behaviour. New York: Longman Publishing Group.

Schofoeld, G., Biggart, L., Ward, E., Scaife, V., Dodsworth, J., Haynes, A., Larsson, B. 2014. Looked After Children and Offending: Reducing Risk and Promoting Resilience. London: BAAF.

Scott, S., Doolan, M., Beckett, C., Harry, S., Cartwright, S., HCA team. 2010. How is parenting style related to child antisocial behaviour? Preliminary findings from the Helping Children Achieve Study. Department for Education.

Scott, S. and Sylva, K. 1998. Supporting Parents on Kids' Education (SPOKES): Improving Adjustment and Raising Attainment in Young Children at School. Interim project report to the Department of Health. London: Department of Health.

Silverman, D. 2004. Qualitative Research: Theory, Method and Practice. SAGE.

Smith, R. 2006. "Welfare versus justice - again!” Youth Justice 5(1): 3-16.

Social Care Institute for Excellence, 20013, Antisocial behaviour and conduct disorders in children and young people: recognition, intervention and management, National Institute for Health and Clinical Excellence.

Stanley, C. 2001. “Will New Justice Work?” Probation Journal 48: 93-101.

Stephenson, M., Giller, H., Brown, S. 2007. Effective Practice in Youth Justice, Cullompton, William.

Taylor J. B., Killick C., MdGlade, A. 2015. Understanding \& using research in social work. London: SAGE.

Taylor Ch. 2016. Review of the Youth Justice Service in England and Wales. Ministry of Justice.

The Children Act. 1908, 1989 \& 2004. HMSO. London.

The Children (Leaving Care) Act. 2000. HMSO. London.

The Crime \& Disorder Act. 1998. HMSO. London.

The Children \& Young Person's Act. 1969. HMSO. London.

The Children and Young Persons Act. 1993. HMSO. London.

The Criminal Justice Act. 2003. HMSO. London.

The Data Protection Act. 1998. HMSO. London.

Thompson, N. 2006. Anti-discriminatory practice. Palgrave Macmillan.

Tierney, J. 2006. Criminology, Theory and Content. London: Longman.

Youth Justice Board. 2009. Children, Schools and Families Committee inquiry into Training of Children and Families Social Workers. Submission by the Youth Justice Board for England and Wales. Accessed online 23/08/16 at 15:38: 
http://www.publications.parliament.uk/pa/cm200809/cmselect/cmchilsch/mem o/trainingsocwor/ucm 2002.htm

Youth Justice Board. 2003. Assessment, Planning Interventions and Supervision, ECOTEC Research and Consulting Ltd and The Nottingham Trent University on behalf of Youth Justice Board for England and Wales.

Youth Justice Board. 2008. An evaluation of social work posts in young offender institutions. Youth Justice Board for England and Wales.

Youth Justice Board. 2000. ASSET: Explanatory Notes Version 1. London: Youth Justice Board for England and Wales.

Youth Justice Board. 2003. Assessment, Planning Interventions and Supervision, ECOTEC Research and Consulting Ltd and The Nottingham Trent University on behalf of Youth Justice Board for England and Wales.

Youth Justice Board. 2010. A Review of YOTs and Children's Services' Interaction with Young Offenders and Young People at Risk of Offending. Youth Justice Board for England and Wales,

Wadsworth, M. 1979. Roots of Delinquency. Oxford: Martin Robertson \& Company Ltd.

West, D.J., Farrington, D.P. 1973. Who Becomes Delinquent. Heinemann Educational Books Ltd.

Wilson K., Ruch, G., Lymbery M., Cooper, A. 2011. Social Work. An introduction to Contemporary Practice. Second Edition. Edinburgh: Pearson Education Limited.

Worron, J. M., Frick, P. J., Shelton, K. K., SIlverthorn, P. 1997. Ineffective parenting and childhood conduct problems: The moderating role of callousunemotional traits. Journal of Consulting and Clinical Psychology 65(2): 301308. 